Socioeconomic Institute

Sozialökonomisches Institut

Working Paper No. 1009

Do Religious Beliefs Explain Preferences for Income Redistribution? Experimental Evidence

Ilja Neustadt

September 2010 
Socioeconomic Institute

University of Zurich

Working Paper No. 1009

Do Religious Beliefs Explain Preferences for Income Redistribution? Experimental Evidence

September 2010

Author's address: Ilja Neustadt

E.mail: ilja.neustadt@soi.uzh.ch

Publisher

Sozialökonomisches Institut

Bibliothek (Working Paper)

Rämistrasse 71

CH-8006 Zürich

Phone: +41-44-634 2137

Fax: +41-44-634 4982

URL: www.soi.uzh.ch

E-mail: soilib@soi.uzh.ch 


\title{
Do Religious Beliefs Explain Preferences for Income Redistribution? Experimental Evidence
}

\author{
Ilja Neustadt*
}

September 29, 2010

Abstract: Due to the mixed empirical evidence bearing on the economic determinants, beliefs have been at the center of attention of research into preferences for income redistribution. We elicit preferences for income redistribution through a Discrete Choice Experiment performed in 2008 in Switzerland and relate them to several behavioral determinants, in particular to religious beliefs. Estimated marginal willingness to pay (WTP) is positive among those who do not belong to a religious denomination, and negative otherwise. However, the marginal WTP is shown to increase with a higher degree of religiosity. Moreover, those who state that luck or connections play a crucial role in determining economic success exhibit significantly higher WTP values than those who deem effort to be decisive.

Keywords: Income redistribution, beliefs, religiosity, welfare state, preferences, willingness to pay, discrete choice experiments

JEL classification: C35, C93, D63, H29

\footnotetext{
${ }^{*}$ Corresponding author Socioeconomic Institute, University of Zurich, Hottingerstrasse 10, 8032 Zurich, Switzerland, Tel. +41-44-634 06 09; Fax: +41-44-634 4987.

E-mail: ilja.neustadt@soi.uzh.ch
} 


\section{Introduction}

Citizens' preferences with regard to income redistribution are of crucial importance for the political debate as to the future of the welfare state. While the typical right-wing stance is to decry it as excessive, the left points to pockets of poverty even in rich societies that need to be eradicated through more redistribution. This paper contributes to this debate by measuring citizens' willingness to pay (WTP) for income redistribution through a Discrete Choice experiment (DCE) and relating it to a set of behavioral determinants. The data come from a DCE performed in the fall of 2008 and involving 979 Swiss citizens.

Recently, there has been a great deal of research into the demand for redistribution and its determinants, which will be discussed in Section 2 below. One line of thought relates the measured amount of redistribution to economic, institutional, and behavioral factors. Examples are Alesina and Giuliano (2009) and Akkoyunlu et al. (2009). However, the observed amount of redistribution is the outcome of an interaction between demand and supply, with supply governed by a country's political institutions and processes. This classical identification problem would have to be addressed in order to make inferences about citizens' preferences for redistribution. A second direction of research, exemplified by Alesina and La Ferrara (2005) and Guillaud (2008), relies on surveys designed to measure attitudes towards redistribution. The problem with this approach is its failure to impose a budget constraint. It therefore cannot predict actual decision making (e.g. voting at the polls), where citizens take the consequences in terms of their own income and wealth into account. A third approach seeks to solve this problem through Contingent Valuation (CV) experiments [see e.g. Boeri et al. $(2001,2002)^{1}$. The weakness of the CV approach is that it holds all the attributes of the good in question constant, varying its price only. One would want to vary other attributes of redistribution besides its tax price, viz. its uses (for

\footnotetext{
${ }^{1}$ Boeri et al. (2001) study international attitudes towards redistribution with a focus on pension and unemployment schemes in France, Germany, Italy, and Spain. They also perform CV experiments that impose an explicit trade-off between income and social insurance coverage on respondents. They find that people oppose an extension of the welfare state, with conflicts between young and old, rich and poor, and insiders and outsiders creating significant hurdles to welfare reform.
} 
health, old age, etc.) and the type of beneficiary (foreigner, national).

By way of contrast, a DCE allows measurement of preferences uncontaminated by supply influences, it imposes the budget constraint through the price attribute, and it does so in a realistic way by making respondents choose between alternatives where all attributes are allowed to vary.

The remainder of this paper is structured as follows. Section 2 contains a literature review from which hypotheses to be tested are derived. Its first part concerns general determinants of the demand for redistribution and the second, its behavioral determinants, in particular, religious denomination, religiosity, and beliefs about the role of luck in achieving

economic success. Section 3 presents a general description of the method of DCEs as well as the design of the present experiment. The descriptive statistics of the experiment follow in Section 4, and hypothesis tests, in Section 5. Section 6 summarizes the results and concludes with summarizes the results and concludes with suggestions for future research.

\section{Literature review and statement of hypotheses}

This section first presents research that defines the general background of this paper and then moves on to contributions that lead to a set of specific hypotheses to be tested.

\subsection{General determinants of the demand for income redistribu- tion}

In their reviews, Alesina and Giuliano (2009) and Akkoyunlu et al. (2009) identify a wide set of factors that can be categorized as economic, political, and behavioral determinants of the demand for income redistribution.

The simplest framework for the analysis of purely economic determinants is provided by a model focusing on current economic well-being, originally proposed by Romer (1975) and Roberts (1977) and extended by Meltzer and Richard (1981) [RRMR model]. This model assumes non-altruistic utility-maximizing individuals differentiated by their income levels 
only. The government pays a lump-sum transfer to all citizens, financed by a linear uniform income tax. Individuals with an income below the mean favor taxation and transfers while those with an income above the mean oppose it. In a political equilibrium, the majority of voters supports a positive tax rate corresponding to the value desired by the median voter. The model's prediction is that the larger the gap between the mean and the median income, the higher the level of taxation and redistribution.

The empirical evidence is quite mixed. On the one hand, Alesina and Rodrik (1994), Persson and Tabellini (1994), and Milanovic (2000) find some supporting evidence. Furthermore, Guillaud (2008), conducting a cross-section analysis of survey data from four EU countries, shows that poorer and less educated individuals are more in favor of redistribution. On the other hand, Alesina and Glaeser (2004), Perotti (1996), and Rodriguez (1999) fail to find supporting evidence for this model. Moreover, Neustadt and Zweifel (2009) relate willingness to pay (WTP) for income redistribution elicited from a Discrete Choice Experiment (DCE, see Section 3.1 for details) to measures of economic well-being. WTP values are negatively related to income and education, contradicting the RRMR model.

Another economic explanation is the "Prospect of Upward Mobility" (POUM) hypothesis, suggested by Hirschman and Rothschild (1973) as the 'tunnel effect' and more recently reformulated by Benabou and Ok (2001). It extends the RRMR model by introducing individuals' expectations, based on their observations regarding the income mobility of others in society. Expected upward mobility may dampen a poor but forward-looking voter's enthusiasm for income redistribution.

Empirical support of the POUM hypothesis is provided by Alesina and La Ferrara (2005) who, using an actual mobility matrix for the United States, show that people who can expect high future income oppose redistribution. Rainer and Siedler (2008) use probabilistic expectations data to show that individuals with a sufficiently large chance of occupational upward mobility exhibit a lower demand for redistribution; conversely, those with a sufficiently large risk of occupational downward mobility opt for more redistribution. Checchi and Filippin (2004), testing the POUM hypothesis by means of a within- 
subjects experiment, find corroborating evidence under several alternative specifications. According to Guillaud (2008), however, individuals who subjectively experienced upward mobility over ten years tend to be more (rather than less) supportive of redistributive policies. Moreover, upward intergenerational mobility in occupational prestige goes along with more positive rather than negative attitude towards redistribution. Alesina and Giuliano (2009) examine the empirical evidence for the United States and briefly across countries, concluding that social mobility (if measured as the change in the occupational prestige) does decrease demand for redistribution once sociodemographic (age, gender, race) and socioeconomic characteristics (income, education) are controlled for. In their DCE-based study, Neustadt and Zweifel (2009) relate preferences for redistribution to mobility. They find partial empirical support for the POUM hypothesis.

Another economic explanation, suggested by the social contract literature, is that preferences for redistribution can at least in part be interpreted as a demand for insurance by risk-averse individuals. In a hypothetical situation, where individuals do not yet know their endowment as well as their future position in society ['veil of ignorance', cf. Rawls (1999)], they are predicted to exhibit positive WTP for an income transfer from more favorable future states to less favorable ones. Redistributive policies can thus be interpreted as reflecting this hypothetical demand for insurance. Beck (1994) investigates individual behavior under the 'veil of ignorance' in an experiment. By placing participants in a hypothetical society with random differences in income, represented by lotteries, he is able to derive the desired amount of income redistribution. Individuals indeed display risk aversion, albeit not of the extreme kind implied by the Rawlsian maximin rule that uses the maximum improvement of the individual with minimum initial wealth as the sole criterion. Furthermore, they show no preference for income redistribution in excess of what can be explained by risk aversion.

As to the political determinants of the demand for income redistribution, literature on political economy [Persson and Tabellini (2000, 2003); Lizzeri and Persico (2001); MilesiFerretti et al. (2002)] predicts that proportional representation tends towards universal programs benefitting various groups (old-age pensioners, working poor, minorities, etc.), 
while majority rule results in targeted "pork barrel" programs. Persson and Tabellini (2003) find supporting empirical evidence in that countries with proportional representation have GDP shares of government expenditure that ceteris paribus are 5 percentage points higher than countries with majority rule. Moreover, Akkoyunlu et al. (2009) present weak evidence of a positive correlation between the degree of proportional representation and the transfer share in GDP in OECD countries. Additional political determinants of redistribution include two-party vs. multiparty system, presidential vs. parliamentary democracy, and direct vs. representative democracy, with two-party systems, presidential, and direct democracies all predicted to induce less public redistribution. In order to sketch the institutional background of the DCE described in Section 3.2, Switzerland can be described as follows. It has a high degree of proportional representation and a parliamentary democracy. Its distinguishing feature, however, is its extensive direct democratic control in the guise of popular initiatives and referenda. This might serve to limit public welfare spending while enforcing efficiency in redistribution [cf. Feld et al. (2007)].

The mixed empirical evidence bearing on the economic determinants of preferences for redistribution calls for a detailed analysis of their behavioral determinants. In particular, beliefs have been at the center of attention. The theoretical base is laid by Alesina and Angeletos (2005), who develop a model where society's belief as to whether effort or luck determines economic success gives rise to multiple self-fulfilling equilibria. Benabou and Tirole (2006) propose a model for the emergence and persistence of such collective beliefs. Moreover, beliefs can be seen as a source of altruistic preferences and inequality aversion. On the empirical side, Fong (2001) presents evidence in line with Alesina and La Ferrara (2005) suggesting that beliefs about the role of luck in determining economic success are an important determinant of the demand for redistribution. She also considers the effects of incentives. If effort determines income, then an increased income tax rate causes an output loss due to its effect on incentives. This consideration is hypothesized to qualify the link between beliefs and the demand for redistribution. However, the data fail to support this hypothesis.

While the POUM hypothesis suggests less redistribution than predicted by the RRMR 
model, the assumption of altruistic preferences can lead to the opposite prediction. In fact, if individuals care also about the utility of others, one might expect more redistribution than predicted by the conventional RRMR model. Fehr and Schmidt (2006) provide a review of several models of social preferences, in particular, altruism, envy, inequality aversion, fairness, and reciprocity. In a simple model of inequality aversion, it is assumed that individuals feel envy if their incomes are below that of others but they feel altruistic when their income exceeds it. Consequently, the decisive median voter demands more redistribution than in the conventional RRMR model.

Based on the assumption of inequality aversion, Neustadt and Zweifel (2010b) formulate two hypotheses to be tested. The first predicts that the citizens with higher inequality aversion exhibit a positive WTP for redistribution while those with lower inequality aversion, a negative one. The second hypothesis is based on the consideration that voters exhibiting inequality aversion tend to support the view that the government should reduce the income gap between rich and poor. Consequently, respondents who state that the reduction of the income gap is a task of the government are expected to exhibit a positive WTP for redistribution.

\subsection{Religious beliefs and demand for income redistribution}

There exists a great deal of theoretical literature dealing with religious beliefs as a determinant of demand for income redistribution, all of them predicting a negative relationship between the degree of religiosity and demand for income redistribution.

In particular, Benabou and Tirole (2006) develop a theory of collective beliefs, based on endogenous complementarities between individual cognitive choices that arise naturally from the interaction of psychological motives and economic rationality. In a simple model, they analyze an important class of religious beliefs that are linked to the 'Protestant work ethic', namely to a belief that there is a world to come, in which rewards and punishments depend on the effort and industriousness of a person during his lifetime ${ }^{2}$. Alternative

\footnotetext{
${ }^{2}$ cf. Weber (1920)
} 
beliefs can be of two kinds: (i) a belief that there is no afterlife (atheism or agnosticism); (ii) a belief that there is afterlife but its rewards are not related to efforts in the current world but might be subject to observance of commandments, good deeds towards other people etc. Thus, the more religious (in the sense of the 'Protestant work ethic') a citizen is, the more effort he exerts. Thus, a more religious individual prefers lower tax rates in order to avoid income redistribution in favor of the less religious citizens who do not work as hard. If a low tax rate decided upon by a majority of religious citizens is anticipated by the population, individuals become more religious since the belief that hard work leads to rewards in afterlife generates higher utility given low income redistribution. Conversely, if a majority of citizens who happen to be less religious votes for a high level of redistribution, it can become profitable to invest in the non-religious beliefs and thus to exert less effort. In sum, two equilibria are possible:

(i) An equilibrium with a high level of religiosity in the sense of the 'Protestant work ethic', implying a high level of work effort and a low level of income redistribution.

(ii) An equilibrium with a low level of religiosity or a predominance of non-Protestant beliefs, implying a low level of work effort and a high level of income redistribution.

Moreover, Scheve and Stasavage (2006a,b) propose a model of religious participation as a substitute for insurance against adverse events. Therefore risk-averse religious individuals desire less demand for redistribution as a collective insurance device, resulting again in a negative predicted relationship between religiosity and redistribution.

A further strand of literature, based on preferences rather than beliefs, argues that public redistribution crowds out religious participation and charitable activities, giving once more rise to a negative correlation. Hungerman (2005) and Gruber and Hungerman (2007) find evidence that public insurance spending indeed crowds out religious charitable spending. Akkoyunlu et al. (2009) empirically relate the amount of public social expenditure to the strength of religious orientation for the OECD countries. They show that the partial correlation between religiosity and the share of transfers in GDP is clearly negative, supporting the theories expounded above. Moreover, Switzerland shares the somewhat 
guarded attitudes prevailing in the EU rather than the highly religious attitudes of the U.S. population. Being located close to the regression line, Switzerland provides additional evidence supporting the theoretical arguments relating religion to redistribution.

Based on the theoretical arguments of Benabou and Tirole (2006) and Scheve and Stasavage (2006a,b), we formulate two hypotheses to be tested in Section 5.2. The first predicts that members of Protestant churches exhibit a negative willingness to pay (WTP) for redistribution while members of other denominations (who do not share the Protestant work ethic but still strongly participate in and profit from private charity), a higher but still a negative one. By way of contrast, citizens with no affiliation at all who presumably share atheistic or agnostic beliefs are predicted to exhibit a strictly positive WTP for redistribution. The second hypothesis predicts the WTP for redistribution to fall with a higher level of religiosity of the individual, alternatively measured as (a) strength of the belief in God, (b) frequency of attending religious services.

Hypothesis 1: Willingness to pay for redistribution is expected to be

(A) negative if the individual belongs to a Protestant church,

(B) negative but less so than in (A) if the individual belongs to a religious denomination other than Protestant,

(C) positive if the individual is unaffiliated.

Hypothesis 2: Willingness to pay for redistribution is expected to decrease with

(a) a stronger belief in God,

(b) more frequent attendance of religious services. 


\subsection{Beliefs about the role of luck and effort and demand for income redistribution}

The Benabou-Tirole model (see Section 2.2) suggests that beliefs about the role of effort in determining economic success or intertemporal utility are an important determinant of the preferences for redistribution. The conviction that high income and wealth are the result of work effort (belief in a just world) goes along with a low level of income redistribution. Conversely, a society that believes that luck, connections, social capital inherited from one's parents, and corruption (realistic pessimism) determine income and wealth is expected to choose a high degree of redistribution, financed by high taxes, see also Alesina and Glaeser (2004) and Alesina and Angeletos (2005). In their model of collective beliefs, Benabou and Tirole (2006) derive two possible equilibria with respect to the belief in a just world:

(i) An equilibrium with optimistic beliefs in a just world and a laissez-faire society arises in a population where the majority of citizens tries to ignore discouraging news about the efficacy of the individual effort. In turn, the majority chooses a relatively low tax rate with little redistribution and thus has strong incentives to believe that the world is indeed just.

(ii) An equilibrium with pessimistic beliefs and a welfare state arises in a population where the majority takes seriously all discouraging news about the efficacy of the individual effort. Thus, the majority chooses a high tax rate with a high level of redistribution.

Empirical evidence suggests that beliefs sharply differ between the United States and the EU. Most Americans believe that anyone can get out of poverty by hard work and that the poor remain poor only because they refuse to make the effort. By way of contrast, Europeans generally think that poverty is due to bad luck and not the individual's responsibility. Fong and Oberholzer-Gee (2007) measure the willingness-to-pay for justice in the United States using dictator games. Dictators were given $\$ 10$ to split between themselves and recipients. The authors find that one third of the dictators are willing to pay one 
dollar out of ten for obtaining the information whether poverty was due to disability or substance abuse. Finally, Alesina and Giuliano (2009) show that a history of misfortune in the recent past such as unemployment and personal trauma makes people more risk-averse and less optimistic about upward mobility. These changes in beliefs are found to have a positive and significant effect on redistribution.

Therefore, the Benabou-Tirole model suggests that equilibrium (i) with a laissez-faire society is likely to persist in the United States while equilibrium (ii) with a full-fledged welfare state is sustainable in Europe. Akkoyunlu et al. (2009) relate the amount of public social spending to a score that ranges from 1 (hard work always brings a better life) to 10 (hard work does not bring any success) using data from OECD countries. The U.S. score is closest to 1 but lies below the regression line, while Germany and Denmark mark the other extreme. Again, as in the case of religiosity, this regression is one of two bestfitting bivariate regressions designed to explain the share of transfers in GDP. Here again,

Switzerland as a test case lies right near the regression line, lending additional support to the hypothesis.

Based on the presented literature review we state Hypothesis 3 to be tested in Section 5.2 as follows.

Hypothesis 3: Willingness to pay for redistribution is expected to increase with a stronger individual belief that luck rather than effort determine economic success.

\section{Discrete choice experiments}

\subsection{Theoretical foundations}

Discrete Choice Experiments (DCEs) provide a tool for measuring individuals' preferences for characteristics of commodities, the so-called attributes. In contradistinction to classical Revealed Preference Theory, originating with Samuelson (1938), DCEs allow individuals to express their preferences for non-marketed as well as hypothetical products. During a DCE, respondents are repeatedly asked to compare the status quo with several hypothetical 
alternatives defined by their attributes including a price. By varying the levels of attributes, different product alternatives are generated. A rational individual will always choose the alternative with the highest utility. From the observed choices, the researcher can infer the utility associated with the attributes. The proposed method, derived from the New Demand Theory of Lancaster (1971), is also known as Conjoint Analysis [Louviere et al. (2000)].

The most prominent alternative to a DCE is Contingent Valuation (CV). A certain situation or product is described in detail, and respondents are asked to indicate their maximum willingness to pay (WTP) for this fixed product. Only its price attribute is varied, while in Conjoint Analysis all relevant attributes are varied simultaneously, making it a multi-attribute valuation method [Merino-Castello (2003)]. While a DCE describes the product in less detail than a typical CV study, it allows for analyzing many product varieties by varying the levels of relevant attributes [Louviere et al. (2000), p. 344]. Tradeoffs among attributes can be explicitly taken into account and WTP values of attributes estimated separately (see below). Furthermore, strategic behavior of respondents is less likely than in CV with its exclusive emphasis on price, which facilitates strategic behavior. Finally, biases that easily occur when individuals are directly asked about their WTP are less frequently observed in a DCE [Ryan (2004)].

A particular advantage of a DCE in the present context is that it permits to explicitly impose the budget constraint through a price attribute in the guise of the tax share of income used to finance the transfers considered. Respondents can be made to simultaneously choose this share and hence the 'size of the pie' and the 'slices of the pie' devoted to different types of recipients and uses (health, old age, etc.; see Exhibits No. 1 to 3 in Appendix). Thus, trade-offs among different attributes of the redistribution plan can be calculated to assess the relative importance of the respective redistributive goals.

The econometric method used is based on the Random Utility Theory [see Luce (1959), Manski and Lerman (1977) and McFadden (1974, 1981, 2001)]. Individual $i$ values alter- 
native $j$ according to the utility $V_{i j}$ attained, which is given by

$$
V_{i j}=v_{i}\left(a_{j}, p_{j}, y_{i}, s_{i}, \varepsilon_{i j}\right)
$$

Here, $v_{i}(\cdot)$ denotes $i$ 's indirect utility function, $a_{j}$, the amount of attributes associated with alternative $j$, and $p_{j}$, price. The individual's income and sociodemographic characteristics are symbolized by $y_{i}$ and $s_{i}$, respectively. Finally, $\varepsilon_{i j}$ denotes the error term, which is due to the fact that the experimenter will never observe all the arguments entering $v_{i}$, imparting a stochastic element to observed choices. As usual, the utility function is additively split into a systematic component $w(\cdot)$ and a stochastic one,

$$
V_{i j}=w_{i}\left(a_{j}, p_{j}, y_{i}, s_{i}\right)+\varepsilon_{i j}
$$

A utility-maximizing individual $i$ will prefer alternative $j$ to alternative $l$ if and only if

$$
w_{i}\left(a_{l}, p_{l}, y_{i}, s_{i}\right)+\varepsilon_{i l} \leq w_{i}\left(a_{j}, p_{j}, y_{i}, s_{i}\right)+\varepsilon_{i j}
$$

Due to the presence of the stochastic term, only the probability $P_{i j}$ of individual $i$ choosing alternative $j$ rather than alternative $l$ can be estimated, with

$$
\begin{aligned}
P_{i j} & =\operatorname{Prob}\left[w_{i}\left(a_{l}, p_{l}, y_{i}, s_{i}\right)+\varepsilon_{i l} \leq w_{i}\left(a_{j}, p_{j}, y_{i}, s_{i}\right)+\varepsilon_{i j}\right] \\
& =\operatorname{Prob}\left[\varepsilon_{i l}-\varepsilon_{i j} \leq w_{i}\left(a_{j}, p_{j}, y_{i}, s_{i}\right)-w_{i}\left(a_{l}, p_{l}, y_{i}, s_{i}\right)\right] .
\end{aligned}
$$

Thus, the probability of choosing $j$ amounts to the probability of the systematic utility difference $w_{i}[j]-w_{i}[l]$ dominating the 'noise', $\varepsilon_{i l}-\varepsilon_{i j}$. By the central limit theorem, the error terms $\left\{\varepsilon_{i l}, \varepsilon_{i j}\right\}$ can be assumed to be normally distributed with mean zero and variances $\sigma_{l}^{2}$ and $\sigma_{j}^{2}$ as well as covariance $\sigma_{l j}$. Under these assumptions, $\varphi_{i j}:=\varepsilon_{i l}-\varepsilon_{i j}$ is also normally distributed with mean zero and variance $\sigma^{2}:=\operatorname{Var}\left[\varphi_{i j}\right]=\sigma_{l}^{2}+\sigma_{j}^{2}-2 \sigma_{l j}$. Thus, equation (4) can be represented as

$$
P_{i j}=\Phi\left(\frac{w_{i}\left(a_{j}, p_{j}, y_{i}, s_{i}\right)-w_{i}\left(a_{l}, p_{l}, y_{i}, s_{i}\right)}{\sigma}\right),
$$

where $\Phi(\cdot)$ denotes the cdf of a standard normal distribution. This model is known as the binary probit model [cf. Ben-Akiva and Lerman (1985)]. Hensher et al. (1999) provide 
empirical evidence that a linear specification of the function $w(\cdot)$ leads to good predictions in its middle ranges. Therefore, in the case of the simple model that relates utilities and choice probabilities to the attributes only (see Section 5.1), one posits

$$
w_{i}\left(a_{j}, p_{j}, y_{i}, s_{i}\right)=c_{i}+\sum_{k=1}^{K} \beta_{k} a_{k j}+\varepsilon_{i j},
$$

where $c_{i}$ represents an individual-specific constant, $a_{k}, k=1, \ldots, K$, are the attributes of the alternative, and $\beta_{k}, k=1, \ldots, K$, are the parameters to be estimated. These parameters can be interpreted as the constant marginal utilities of the corresponding attributes. One obtains the following expression representing the difference in utility of individual $i$ between alternative $j$ and status quo,

$$
\Delta V_{i j}=c_{i}+\sum_{k=1}^{K} \beta_{k} \Delta a_{k j}+\beta_{p} \Delta p_{j}+\varphi_{i j}
$$

where $\Delta a_{k j}=a_{k j}-a_{l j}, \Delta p_{j}=p_{j}-p_{l}, c_{i}=c_{i l}-c_{i j}$, and $\varphi_{i j}=\varepsilon_{i l}-\varepsilon_{i j}$ for each $j \neq l$. The marginal rate of substitution between two attributes $m$ and $n$ is given by

$$
\mathrm{MRS}_{m, n}=-\frac{\partial v / \partial a_{m}}{\partial v / \partial a_{n}}
$$

Therefore, the marginal WTP for attribute $a_{m}$ can be calculated by dividing the marginal utility of this attribute by the marginal utility of the price attribute [in the present context, the income tax rate, see e.g. Telser (2002), p. 56]:

$$
\operatorname{MWTP}\left(a_{m}\right)=\frac{\partial v / \partial a_{m}}{\partial v / \partial p_{j}} .
$$

For econometric inference, it is important to recall that the same individual makes several choices. The two-way random-effect specification takes this into account with $\varphi_{i j}=$ $\mu_{i}+\eta_{i j}$, where $\mu_{i}$ denotes the component that varies only across individuals but not across the choice alternatives. The terms $\mu_{i}$ and $\eta_{i j}$ are assumed uncorrelated with the product attributes $\left(a_{i 1}, \ldots, a_{i K}\right)$ and between themselves. By a standard assumption in a probit model, $\sigma_{\eta}=1$. Hence $\operatorname{Var}\left[\varphi_{i j}\right]=\sigma_{\eta}^{2}+\sigma_{\mu}^{2}=1+\sigma_{\mu}^{2}$ and $\operatorname{Corr}\left[\varphi_{i j}, \varphi_{i l}\right]=\frac{\sigma_{\mu}^{2}}{1+\sigma_{\mu}^{2}}=: \rho$. The parameter $\rho$ indicates how strongly the various responses of an individual are correlated 
with each other, or, equivalently, the share of the total variance that can be explained by individual-specific error term. The random-effects specification is justified if $\rho$ is high and significant.

The simple model can be extended by including various socioeconomic variables (e.g. income group, level of education, social mobility). These variables need to be interacted with the product attributes as well as with the constant, giving rise to the extended model specification which allows to check for preference heterogeneity and thus to test Hypotheses 1 to 3 in Section 5.2. By means of a $t$ test we can investigate whether the differences in marginal WTP values between different socioeconomic groups are statistically significant. The computation of the variance of the marginal WTP values is performed by the delta method, cf. Hole (2007).

\subsection{Experimental design}

The experiment was conducted with a representative sample of 979 respondents in the fall of 2008. Initially, the respondents were provided with full decision sets including graphical representations of the status quo and alternatives and were asked to submit their binary choices during a telephone survey. In order to make sure that decisions were based on a homogeneous information set and made in a consistent way, the respondents additionally received a detailed description of the attributes and their possible realizations. The Appendix shows the graphical representation of the status quo (Exhibit 1) and two selected alternatives (Exhibits 2 and 3). The data collection followed in a telephone survey some days later and additionally included a questionnaire covering a wide range of socioeconomic and behavioral characteristics of the respondents.

Prior to the experiment, the attributes and their levels used to define 'income redistribution' had been checked in two pretests for their relevance. Attributes form four groups (see Table 1).

1. Shares of the total redistribution budget to be spent on five types of recipients (viz. the working poor, the unemployed, old-age pensioners, families with children, and 


\begin{tabular}{|l|l||r|r|}
\hline Attribute & Label & Status Quo Level & Alternative Levels \\
\hline Shares of benefits going to & & & \\
- Working Poor & W_POOR & $10 \%$ & $5 \%, 15 \%$ \\
- Unemployed & UNEMP & $15 \%$ & $5 \%, 25 \%$ \\
- Old-Age Pensioners & PENS & $45 \%$ & $35 \%, 55 \%$ \\
- Families with Children & FAM & $5 \%$ & $10 \%$ \\
- People with Ill Health & ILL & $25 \%$ & $20 \%, 30 \%$ \\
\hline Shares of benefits going to & & & \\
- Swiss citizens & SWISS & $75 \%$ & $50 \%, 85 \%$ \\
- Western European foreigners & WEU_FOR & $10 \%$ & $5 \%, 20 \%$ \\
- Other foreigners & OTH_FOR & $15 \%$ & $10 \%, 20 \%$ \\
\hline Total amount of redistribution & REDIST & $25 \%$ (of GDP) & $10 \%, 20 \%, 30 \%, 40 \%, 50 \%$ \\
\hline Income tax & TAX & $25 \%$ (of personal income) & $10 \%, 15 \%, 40 \%$ \\
\hline
\end{tabular}

Table 1: Attributes and their levels

people with ill health);

2. Shares of the total redistribution budget to be spent on three groups (viz. Swiss citizens, western European foreigners, and other foreigners);

3. Total amount of redistribution, defined as a share of GDP;

4. Personal income tax rate to be paid by the respondent (the price attribute).

Clearly, these attributes and their levels combine to form a total number of possible scenarios that cannot be realized in an experiment. The scenarios define the $n$ rows of the observation matrix $X$, with associated covariance matrix $\Omega=\sigma^{2}\left(X^{\prime} X\right)^{-1}$ of parameters $\beta$ to be estimated. So-called $D$-efficient design calls for the minimization of the geometric mean of the eigenvalues of $\Omega$,

$$
D \text { efficiency }=\left(|\Omega|^{\frac{1}{K}}\right)^{-1}
$$

where $K$ denotes the number of parameters to be estimated [cf. Carlsson and Martinsson (2003)]. Using this optimization procedure and incorporating several restrictions, the number of alternatives was reduced to 35 and randomly split into five groups. One alternative 
was included twice in each decision set for a consistency test, resulting in 8 binary choices per respondent.

In order to make sure that decisions were based on a homogeneous information set and made in a consistent way, respondents were provided with a detailed description of the attributes and their possible realizations. The Appendix shows the graphical representation of the status quo (Exhibit 1) and two selected alternatives (Exhibits 2 and 3).

\section{Descriptive statistics}

\subsection{Socioeconomic characteristics}

The sample consists of 979 respondents, 70 percent of them residing in the Germanspeaking part and 30 percent in the French-speaking part of Switzerland. Some 94 percent were born in the country, 50 percent are men, 20 percent having a monthly income below CHF 2,000 and 23 percent, above CHF 6,000, reflecting the structure of the Swiss population. However, only 1.5 percent of the respondents are unemployed.

\begin{tabular}{|r||c|c|}
\hline Religious denomination & No. & \% of valid answers \\
\hline \hline Roman Catholic Church & 383 & 39 \\
Reformed Church & 494 & 51 \\
Unaffiliated & 80 & 8 \\
Other & 19 & 2 \\
\hline \hline Total valid answers & 976 & 100 \\
\hline Missing & 3 & \\
\hline \hline Sample & 979 & \\
\hline
\end{tabular}

Table 2: Religious denomination of the respondents

39 percent of the respondents are members of the Roman Catholic Church while 51 percent belong to the Reformed Church $^{3}$. An additional 2 percent are members of other religious denominations while 8 percent are not affiliated [see Table 2]. As to the strength

\footnotetext{
${ }^{3}$ Largest Protestant denomination in Switzerland.
} 


\begin{tabular}{|r||c|c|}
\hline strength of the belief & No. & $\%$ of valid answers \\
\hline \hline no or weak belief & 382 & 39 \\
moderate belief & 384 & 39 \\
strong or very strong belief & 209 & 22 \\
\hline \hline total valid answers & 975 & 100 \\
\hline missing & 4 & \\
\hline \hline sample & 979 & \\
\hline
\end{tabular}

Table 3: Level of respondents' religiosity measured as strength of their belief in God

\begin{tabular}{|r||c|c|}
\hline Last attendance & No. & \% of valid answers \\
\hline \hline less than 1 month ago & 236 & 27 \\
1 to 2 months ago & 193 & 22 \\
3 to 6 months ago & 236 & 27 \\
more than 6 months ago & 205 & 24 \\
\hline \hline total valid answers & 870 & 100 \\
\hline Missing & 109 & \\
\hline \hline Sample & 979 & \\
\hline
\end{tabular}

Table 4: Level of respondents' religiosity measured by time of their last attendance of a religious service

of religious beliefs, 39 percent indicated no or weak belief in God as well as moderate belief while 22 percent of respondents claimed to have a strong or a very strong belief in God [see Table 3]. Moreover, 27 percent of respondents attended a religious service at least once in the last month. Individuals' shares whose last service attendance was 1 to 2 months ago and 3 to 6 months ago made up 27 and 22 percent, respectively [see Table 4]. Finally, 24 percent stated not having attended a service within the last 6 months. However, the number of missing answers with 109 is unusually high, probably due to the fact that many individuals who never attended a religious service preferred to refuse their answers.

Table 5 shows the distribution of answers to the question, "Is work effort or luck and connections more important for economic success?", with step 1 indicating the belief that work effort alone determines success, and step 10, the opposite belief that work effort does 


\begin{tabular}{|r||c|c|}
\hline & No. & \% of valid answers \\
\hline \hline steps 1 to 2 & 247 & 25 \\
step 3 & 226 & 23 \\
steps 4 to 5 & 389 & 40 \\
steps 6 to 10 & 112 & 12 \\
\hline \hline total valid answers & 974 & 100 \\
\hline Missing & 5 & \\
\hline \hline Sample & 979 & \\
\hline
\end{tabular}

Table 5: Belief whether effort or luck determine economic success on a scale from 1 to 10. Step 1 indicates the belief that only effort determines success, step 10 indicates the belief that only luck determines success.

not matter at all. The majority of respondents seem to believe in the role of effort. In fact, 25 percent of respondents placed themselves on steps 1 or 2,23 percent, on step 3, and 16 percent, on step 4. As much as 24 percent chose step 5 while only 12 percent placed themselves on steps 6 to 10 .

\subsection{Respondents' choice behavior}

There is a total of $979 \cdot 8=7,832$ decisions, of which not quite 20 percent were made in favor of an alternative over the status quo [see Table 6]. There are at least three explanations for this low percentage. First, in spite of checking in the pretests, the levels of the attributes in the experiment may not have been sufficiently spaced apart to make respondents switch. Second, some attributes (e.g. benefits going to the unemployed; see Table 8), may not have been important enough to cause a switch. Finally, there may be errors in decision making because the consistency test revealed 14 percent of choices to be inconsistent. However, there may simply be marked status quo bias in the face of highly complex decision-making situations, as suggested by the large negative constant in Table 8. Nonetheless, only 21 percent of respondents never opted for an alternative [see Table 6]. Conversely, almost 80 percent departed from the status quo at least once. 


\begin{tabular}{|c||c|c|}
\hline Choices & No. & in percent \\
\hline \hline for alternative & 1,562 & 19.94 \\
for status quo & 6,088 & 77.73 \\
No decision & 182 & 2.32 \\
\hline \hline Total & 7,832 & 100 \\
\hline
\end{tabular}

Table 6: Total number of choices

\begin{tabular}{|c||c|c|}
\hline \# choices for alternative & No. & in percent \\
\hline \hline 0 & 209 & 21.35 \\
1 & 309 & 31.56 \\
2 & 226 & 23.08 \\
3 & 131 & 13.38 \\
4 & 57 & 5.82 \\
5 & 16 & 1.63 \\
6 & 10 & 1.02 \\
7 & 0 & 0.00 \\
8 & 5 & 0.51 \\
\hline \hline Total valid answers & 965 & 98.57 \\
\hline Missing & 14 & 1.43 \\
\hline \hline Sample & 979 & 100 \\
\hline
\end{tabular}

Table 7: Distribution of the number of chosen alternatives per respondent

\section{Estimation results}

\subsection{Simple model: preferences of an average respondent}

Estimation of equation (7) includes REDIST ${ }^{2}$ to allow for a possible nonlinearity of the indirect utility function with regard to the GDP share of redistribution REDIST. Moreover, the fact that uses and types of beneficiaries add up to 100 percent needs to be taken into account [see Table 1]. In order to avoid perfect collinearity, PENS (Pensioners) and 


\begin{tabular}{|l||c|c|c|c|c|}
\hline Variable & Coeff. & Std. err. & $z$ & $P>|z|$ & Marg. eff. \\
\hline \hline Recipients' Social Group & & & & & \\
\hline W_POOR & 0.02784 & 0.00714 & 3.90 & 0.000 & 0.00697 \\
UNEMP & 0.01134 & 0.00452 & 2.51 & 0.012 & 0.00284 \\
ILL & 0.01600 & 0.00463 & 3.46 & 0.001 & 0.00400 \\
FAM & 0.06378 & 0.00942 & 6.77 & 0.000 & 0.01596 \\
\hline Recipient's Nationality & & & & & \\
\hline SWISS & 0.03656 & 0.00552 & 6.63 & 0.000 & 0.00915 \\
WEU_FOR & 0.02925 & 0.00869 & 3.37 & 0.001 & 0.00732 \\
\hline REDIST & -0.00523 & 0.00176 & -2.97 & 0.003 & -0.00131 \\
REDIST & & & & & \\
TAX & -0.06619 & 0.01174 & -5.64 & 0.000 & -0.01656 \\
ConSTANT & -0.02053 & 0.00183 & -11.21 & 0.000 & -0.00514 \\
\hline
\end{tabular}

\begin{tabular}{ll} 
\# observations & 7,650 \\
Log likelihood & $-3,566.76$ \\
$\chi^{2}(0)$ & 108.87 \\
Prob $>\chi^{2}$ & 0.000 \\
$\sigma_{u}$ & 0.41610 \\
$\rho$ & 0.14759 \\
\hline
\end{tabular}

Table 8: Random effects probit estimates for the simple model

OTH_FOR (Other foreigners) were dropped to obtain

$$
\begin{aligned}
\Delta V= & c_{0}+\beta_{1} \text { W_POOR }+\beta_{2} \text { UNEMP }+\beta_{3} \mathrm{ILL}+\beta_{4} \mathrm{FAM}+ \\
& +\gamma_{1} \text { SWISS }+\gamma_{2} \text { WEU_FOR }+ \\
& +\delta_{1} \text { REDIST }+\delta_{2} \text { REDIST }^{2}+\eta \mathrm{TAX}+\varphi
\end{aligned}
$$

Estimation of a few of the $5 \cdot 3=15$ specifications with alternative exclusions produced results similar to those displayed in Table 8. Specifically, they agree in that alternatives with additional redistribution are chosen with a lower probability [for details with regard to 'slices' of the pie, see Neustadt and Zweifel (2010a)]. Also, note the sizeable and highly significant coefficient of the price attribute TAX, which is important for the estimation of marginal willingness-to-pay (MWTP) values [see eq. (9)]. For redistribution, the MWTP 
value is given by

$$
\operatorname{MWTP}_{\mathrm{REDIST}}=\frac{\partial \Delta V / \partial \mathrm{REDIST}}{\partial \Delta V / \partial \mathrm{TAX}}=-\frac{\delta_{1}+2 \delta_{2} \mathrm{REDIST}}{\eta}
$$

This amounts to -0.25 percentage points of income share per additional percentage point of GDP devoted to redistribution in excess of the status quo. Evaluated at the mean personal income of the sample, this equals CHF -11.78 per month. However, this figure is dwarfed by the compensation one would have to pay respondents to depart from the status quo,

amounting to an estimated 63 percent of their monthly income, or 5.27 percent of their annual income [see the large negative constant in Table 8].

Neustadt and Zweifel (2010b) construct the (quadratic) WTP function and show that it attains a maximum at $21.05 \%$ of GDP, definitely below the current value of $25 \%$. Therefore, they argue that Swiss welfare state is too big in the light of average citizens' preferences.

\subsection{Extended model: preference heterogeneity}

\subsubsection{Religious denomination and preferences for redistribution}

The simple model is now extended by including dummies for the religious denomination [see Table 2]. The four levels of this variable are represented by three dummy variables, REF, CATH, and OTH_DEN. For instance, the former is defined as

$$
\mathrm{CATH}= \begin{cases}1 & \text { if the respondent belongs to the Catholic Church } \\ 0 & \text { otherwise. }\end{cases}
$$

The reference category is UNAFF (unaffiliated), indicating that the respondent does not belong to a religious denomination. Since an attribute's marginal utility may vary with religious denomination, eq. (10) is modified to also contain interaction terms involving the denomination variables, resulting in

$$
\begin{aligned}
\Delta V^{\prime}= & c_{0}^{\prime}+\cdots+\alpha_{1}^{\prime} \mathrm{CATH}+\cdots+\alpha_{2}^{\prime} \mathrm{REDIST}^{+}+\alpha_{3}^{\prime} \mathrm{REDIST}^{2}+\ldots \\
& +\lambda_{2}^{\prime} \mathrm{REDIST} \cdot \mathrm{CATH}+\lambda_{3}^{\prime} \mathrm{REDIST}^{2} \cdot \mathrm{CATH}^{\mathrm{R}}+\ldots \\
& +\lambda_{4}^{\prime} \mathrm{REDIST} \cdot \mathrm{REF}+\lambda_{5}^{\prime} \mathrm{REDIST}^{2} \cdot \mathrm{REF}+ \\
& +\lambda_{6}^{\prime} \mathrm{REDIST} \cdot \mathrm{OTH} \_\mathrm{DEN}+\lambda_{7}^{\prime} \mathrm{REDIST}^{2} \cdot \mathrm{OTH}+\mathrm{DEN}+\cdots+\varphi^{\prime} .
\end{aligned}
$$




\begin{tabular}{|l||c|c|c|c|l|}
\hline & exp. sign & MWTP, \% of income & MWTP, CHF & s.e., CHF & \\
\hline \hline Catholics & - & -0.32857 & -15.44 & 7.34 & $* * *$ \\
Reformed & - & -0.47866 & -21.33 & 11.24 & $* * *$ \\
Unaffiliated & + & 0.71988 & 37.77 & 9.77 & $* * *$ \\
Others & & -1.15630 & -49.30 & 86.45 & \\
\hline
\end{tabular}

Note: ${ }^{* * *}$ denotes statistical significance of MWTP in $\%$ of income at the 1 percent level.

Table 9: Marginal WTP values for redistribution (in percent of monthly personal income and $\mathrm{CHF}$ ) derived from the extended model with religious denominations

Hypothesis 1(A) states that the demand for redistribution is expected to be negative for the respondents belonging to the Reformed Church. It is confirmed, with the MWTP for one percentage point increase of the total amount of redistribution being a negative CHF -15.44 [see Table 9]. Hypothesis 1(B), stating that Catholics exhibit a negative demand for redistribution that is, however, higher than that of the Protestants is confirmed, too. However, a $t$ test shows that the difference in MWTP values between these two religious groups is statistically not significant. Further, Hypothesis 1(C), predicting the demand for redistribution of unaffiliated citizens to be positive finds strong empirical support with the corresponding MWTP of CHF 37.77 for one percentage point increase of the total amount of redistribution. Moreover, $t$ tests confirm that MWTP values of the unaffiliated individuals on the one side and Catholics or Reformed on the other side are significantly different (with $t$ values of 4.35 and 3.97 , respectively).

\subsubsection{Religiosity and preferences for redistribution}

In this section, the simple model is extended by one of two measures of religious participation by including the corresponding dummies [see Tables 3, 4]. For instance, in the case of the strength of religious beliefs, the three levels of this variable are represented by two dummy variables, namely WEAK (no or weak belief in God) and STRONG (strong or 
very strong belief), with the former being defined as

$$
\text { WEAK }= \begin{cases}1 & \text { if the respondent has no or weak belief in God } \\ 0 & \text { otherwise }\end{cases}
$$

Here, the reference category is MODER, indicating that the respondent stated having beliefs of moderate strength. Since an attribute's marginal utility may vary with religious denomination, eq. (10) is modified to also contain interaction terms involving the denomination variables, resulting in

$$
\begin{aligned}
\Delta V^{\prime \prime}= & c_{0}^{\prime \prime}+\cdots+\alpha_{1}^{\prime \prime} \mathrm{WEAK}+\cdots+\alpha_{2}^{\prime \prime} \mathrm{REDIST}+ \\
& +\alpha_{3}^{\prime \prime} \mathrm{REDIST}^{2}+\cdots+\kappa_{2}^{\prime \prime} \mathrm{REDIST} \cdot \mathrm{WEAK}+ \\
& +\kappa_{3}^{\prime \prime} \mathrm{REDIST}{ }^{2} \cdot \mathrm{WEAK}+\cdots+ \\
& +\kappa_{4}^{\prime \prime} \mathrm{REDIST} \cdot \mathrm{STRONG}+ \\
& +\kappa_{5}^{\prime \prime} \mathrm{REDIST}^{2} \cdot \mathrm{STRONG}^{\mathrm{R}}+\cdots+\varphi^{\prime \prime}
\end{aligned}
$$

\begin{tabular}{|l|c|c|c|c|}
\hline & MWTP, \% of income & MWTP, CHF & s.e., CHF & \\
\hline \hline no or weak belief & -0.47477 & -20.67 & 12.75 & $* *$ \\
moderate belief & -0.42066 & -19.33 & 7.93 & $* * *$ \\
strong belief & 0.24983 & 12.83 & 8.56 & $*$ \\
\hline
\end{tabular}

Note: $* * *(* * *)$ denotes statistical significance of MWTP in $\%$ of income at the $1(5,10)$ percent level.

Table 10: Marginal WTP values for redistribution (in percent of monthly personal income and $\mathrm{CHF}$ ) derived from the extended model with strength of religious beliefs

Hypothesis 2(a) with its focus on the degree of religiosity as a determinant of WTP for redistribution states that the demand for redistribution is expected to decrease with a stronger belief in God. The estimated WTP values suggest to reject this hypothesis, however. In fact, the WTP increases with the strength of religious beliefs [see Table 10]. The $t$ test for preference heterogeneity confirms that the WTP of individuals with strong 
beliefs significantly differs from the WTP of the other two groups. However, the difference between respondents with weak and moderate beliefs, respectively, cannot be shown to be statistically significant.

\begin{tabular}{|l||c|c|c|c|}
\hline & MWTP, \% of income & MWTP, CHF & s.e., CHF & \\
\hline \hline less than 1 month ago (group 1) & -0.90140 & -38.47 & 38.43 & $*$ \\
1 to 2 months ago (group 2) & -0.35836 & -15.54 & 12.52 & $*$ \\
3 to 6 months ago (group 3) & -0.44118 & -20.64 & 10.02 & $* * *$ \\
more than 6 months ago (group 4) & -0.05989 & -2.95 & 7.38 & \\
\hline
\end{tabular}

Note: $* * *(* *, *)$ denotes statistical significance of MWTP in $\%$ of income at the $1(5,10)$ percent level.

Table 11: Marginal WTP values for redistribution (in percent of monthly personal income and $\mathrm{CHF}$ ) derived from the extended model with frequency of attending a religious service

Hypothesis 2(b) states that WTP values are predicted to decrease with a higher frequency of attendance of religious services. In fact, the estimated WTP values [see Table 11] seem to confirm this hypothesis. However, as indicated by the test for heterogeneity, the confidence intervals of the estimated WTP values overlap, with the notable exception of group 3 and group 4 exhibiting a weakly significant difference.

\subsubsection{Beliefs about the role of luck and effort and preferences for redistribu- tion}

Next, the simple model is extended by including the dummy variables describing the respondents' beliefs about the role of effort vs. luck for achieving economic success. There are five corresponding dummy variables defined as follows: LUCK12 (=1 if the respondent placed himself on steps 1 or 2 on a scale from 1 to 10, =0 otherwise), LUCK3, (=1 if the respondent placed himself on step $3,=0$ otherwise $\left.{ }^{4}\right)$, and LUCK6 $+(=1$ if the respondent placed himself on steps 6 to 10, thereby indicating a strong belief in luck, $=0$ otherwise) as well as their interactions with the attributes. The reference category is LUCK45 (=1

\footnotetext{
${ }^{4}$ For the distribution of answers, see Table 5.
} 
if the respondent placed himself on steps 4 or $5,=0$ otherwise). Thus, eq. (10) is modified to read,

$$
\begin{aligned}
\Delta V^{\prime \prime \prime}= & c_{0}^{\prime \prime \prime}+\cdots+\alpha_{1}^{\prime \prime \prime} \operatorname{LUCK} 12+\cdots+\alpha_{2}^{\prime \prime \prime} \operatorname{REDIST}+ \\
& +\alpha_{3}^{\prime \prime \prime} \mathrm{REDIST}^{2}+\cdots+\kappa_{2}^{\prime \prime \prime} \mathrm{REDIST} \cdot \mathrm{LUCK} 12+ \\
& +\kappa_{3}^{\prime \prime \prime} \mathrm{REDIST}^{2} \cdot \mathrm{LUCK} 12+\cdots+\varphi^{\prime \prime \prime}
\end{aligned}
$$

\begin{tabular}{|l||c|c|c|l|}
\hline & MWTP, \% of income & MWTP, CHF & s.e., CHF & \\
\hline \hline steps 1 or 2 (group I) & -0.74183 & -32.92 & 13.25 & $* * *$ \\
step 3 (group II) & -0.59576 & -27.23 & 13.63 & $* * *$ \\
steps 4 or 5 (group III) & -0.06592 & -3.08 & 8.12 & \\
steps 6 to 10 (group IV) & 0.71922 & 35.15 & 11.83 & $* * *$ \\
\hline
\end{tabular}

Note: $* * *(* *, *)$ denotes statistical significance of MWTP in $\%$ of income at the $1(5,10)$ percent level.

Table 12: Marginal WTP values for redistribution (in percent of monthly personal income and $\mathrm{CHF}$ ) derived from the extended model with beliefs as to whether effort or luck determine economic success. A higher step indicates a weaker belief in a just world and a stronger belief in luck.

Hypothesis 3 states that the demand for redistribution is predicted to increase with a stronger belief that luck determines economic success. Therefore, respondents who chose higher steps on a scale from 1 to 10 are expected to exhibit higher WTP values. As indicated by the estimation results presented in Table 12, this hypothesis is confirmed. In particular, individuals who placed themselves on steps 6 to 10, thereby indicating that they deem luck and connections to be crucial in the determination of income and wealth, exhibit a strongly positive marginal WTP value of CHF 35.15 for a 1 percentage point increase in the amount of redistribution as a share of GDP. The corresponding MWTP values for other groups, while being negative, do increase with higher steps. Furthermore, the $t$ test results confirm that all differences between the MWTP values of the four groups 
are significant, the only exception being the difference between group I (steps 1 or 2) and group II (step 3), both believing in a just world.

\section{Conclusion and discussion}

In this paper, we elicited citizens' willingness to pay (WTP) for redistribution through a Discrete Choice experiment performed in 2008. Based on a simple model that relates choices to the attributes of redistribution only, the average Swiss citizen would have to be paid a compensation of CHF 11.78 (some US\$ 9.40) per month (0.25 percent of monthly income) for an additional percentage point of GDP devoted to public redistribution. In addition, a very marked status quo bias would have to be overcome by payment of another 63 percent of monthly income.

Furthermore, we tested several hypotheses concerning the behavioral determinants of the demand for redistribution without any confounding supply-side influences. In particular, Hypothesis 1 states that it is negative among church members and positive among those without religious affiliation. An extended model that includes the pertinent variable indicating religious denomination as a regressor yields confirming evidence for this statement; however, the additional prediction that Protestants exhibit a lower WTP than Catholics finds only partial support with the respective difference between the WTP values being statistically not significant. Hypothesis 2 predicts that more religious citizens who are more likely to engage in private charity and frequently consider religion as a means of insurance (crowding-out effect) demand a lower level of public redistribution. Here, the extended version of the model (in both alternative versions) does not support the hypothesis. Finally, Hypothesis 3 predicts that citizens with a strong belief that luck rather than effort determine economic success exhibit a higher WTP. The corresponding extended model that includes the stated belief about the role of luck as a determinant of income and wealth confirms this hypothesis. In fact, Hypothesis 3 is the most successful one in predicting the citizens' demand for redistribution, providing corroborating evidence for the theoretical model of collective beliefs developed by Benabou and Tirole (2006). 
The analysis presented in this paper is subject to several limitations. First, only some behavioral explanations of the demand for redistribution were tested while others (risk aversion, inequality aversion) were not controlled for. Furthermore, as suggested by recent contributions to literature in the field of public choice, citizens' preferences can be importantly influenced by political institutions, in particular by party programs [see e.g. Schläpfer et al. (2007)]. Thus, future work should be devoted to a detailed analysis of individuals' political preferences in order to find out whether these factors also influence stated WTP for redistribution. This analysis would, however, require addressing the identification problem once again, since the supply of public redistribution is governed by political institutions. Second, the status quo bias found in this paper calls for more detailed analysis. To the extent that it reflects risk aversion, it should induce demand for redistribution - contrary to the results presented here. One possible explanation why the status quo bias is so high can be the fact that there are some preferences that are not fully formed [see e.g. Stutzer et al. (2007)]. Another possible explanation might be the redistribution illusion, namely the fact that some respondents are not aware of the actual status quo. Finally, our evidence only relates to a point of time in one country and thus may be subject to transitory shocks and country-specific influences. Still, by appealing to citizens' stated preferences, the present contribution sheds some light on the question whether religious and cultural beliefs can explain preferences for income redistribution.

\section{Acknowledgements}

The author gratefully acknowledges financial support from the Swiss National Science Foundation (SNF) under Project no. 100012-116398. He received helpful comments from Martin Beckmann, Douglas Bernheim, Joan Costa-i-Font, Mireia Jofre-Bonet, Reinhard Madlener, Erik Schokkaert and Peter Zweifel as well as from participants in the Workshop on Behavioural Welfare Economics (Venice Summer Institute, Venice, Italy, 21-22 July 2010), organized by Joan Costa-i-Font and Frank Cowell. 


\section{References}

Akkoyunlu, S., I. Neustadt, and P. Zweifel (2009). Why Does the Amount of Income Redistribution Differ between United States and Europe? The Janus Face of Switzerland. SOI Working Paper No. 0810, University of Zurich, Socioeconomic Institute.

Alesina, A. and G.-M. Angeletos (2005). Fairness and Redistribution. The American Economic Review 95(4), 960-980.

Alesina, A. and P. Giuliano (2009). Preferences for Redistribution. Working Paper.

Alesina, A. and E. Glaeser (2004). Fighting Poverty in the US and Europe: A World of Difference. Oxford University Press.

Alesina, A. and E. La Ferrara (2005). Preferences for Redistribution in the Land of Opportunities. Journal of Public Economics 89, 897-931.

Alesina, A. and D. Rodrik (1994). Distributive Politics and Economic Growth. Quarterly Journal of Economics 109(1), 465-490.

Beck, J. H. (1994). An Experimental Test of Preferences for the Distribution of Income and Individual Risk Aversion. Eastern Economic Journal 20(2), 131-145.

Ben-Akiva, M. E. and S. R. Lerman (1985). Discrete Choice Analysis. MIT Press.

Benabou, R. and E. Ok (2001). Social Mobility and the Demand for Redistribution: the POUM Hypothesis. Quarterly Journal of Economics 116(2), 447-487.

Benabou, R. and J. Tirole (2006). Belief in a Just World and Redistributive Politics. Quarterly Journal of Economics 121(2), 699-746.

Boeri, T., A. Boersch-Supan, and G. Tabellini (2002). Pension Reforms and the Opinions of European Citizens. The American Economic Review 92(2), 396-401. 
Boeri, T., A. Boersch-Supan, G. Tabellini, K. O. Moene, and B. Lockwood (2001). Would You Like to Shrink the Welfare State? A Survey of European Citizens. Economic Policy 16(32), 7-50.

Carlsson, F. and P. Martinsson (2003). Design Techniques for Stated Preference Methods in Health Economics. Health Economics 12, 281-294.

Checchi, D. and A. Filippin (2004). An Experimental Study of the POUM Hypothesis. Research on Economic Inequality 11, 115-136.

Fehr, E. and K. Schmidt (2006). Handbook on the Economics of Giving, Altruism and Reciprocity, Volume 1, Chapter 8, The Economics of Fairness, Reciprocity and Altruism: Experimental Evidence. North-Holland.

Feld, L. P., J. A. Fischer, and G. Kirchgaessner (2007). The Effect of Direct Democratic Institutions on Income Redistribution: Evidence for Switzerland. Working Paper Series in Economics and Finance 689, Stockholm School of Economics.

Fong, C. (2001). Social Preferences, Self-Interest, and the Demand for Redistribution. Journal of Public Economics 82, 225-246.

Fong, C. and F. Oberholzer-Gee (2007). Willingness to Pay for Justice: Evidence from an Experiment on Giving to the Poor. Working Paper.

Gruber, J. and D. M. Hungerman (2007). Faith-Based Charity and Crowd Out during the Great Depression. Journal of Public Economics 91(5-6), 1043-1069.

Guillaud, E. (2008). Preferences for Redistribution: a European Comparative Analysis. Working Paper.

Hensher, D. A., J. J. Louviere, and J. D. Swait (1999). Combining Sources of Preference Data. Journal of Econometrics 89(1-2), 197-221.

Hirschman, A. and M. Rothschild (1973). The Changing Tolerance of Income Inequality in the Course of Economic Development. Quarterly Journal of Economics 87(4), 544-566. 
Hole, A. R. (2007). A Comparison of Approaches to Estimating Confidence Intervals for Willingness to Pay Measures. Health Economics 16, 827-840.

Hungerman, D. M. (2005). Are Church and State Substitutes? Evidence from the 1996 Welfare Reform. Journal of Public Economics 89, 2245-2267.

Lancaster, K. (1971). Consumer Demand: A New Approach. Columbia University Press.

Lizzeri, A. and N. Persico (2001). The Provision of Public Goods under Alternative Electoral Incentives. The American Economic Review 91 (1), 225-239.

Louviere, J. J., D. A. Hensher, and J. D. Swait (2000). Stated Choice Methods - Analysis and Application. Cambridge University Press.

Luce, D. (1959). Individual Choice Behavior. Wiley and Sons, New York.

Manski, C. F. and S. F. Lerman (1977). The Estimation of Choice Probabilities from Choice Based Samples. Econometrica 45(8), 1977-1988.

McFadden, D. (1974). Conditional Logit Analysis of Quantitative Choice Behavior. in: Frontiers of Economics,, 105-142. ed. P. Zarembka, Academic Press, New York.

McFadden, D. (1981). Econometric Models of Probabilistic Choice. in: Structural Analysis of Discrete Data with Econometric Applications,, 198-272. ed. by Ch. Manski and D. McFadden, MIT Press.

McFadden, D. (2001). Economic Choices. The American Economic Review 91 (3), 351-378.

Meltzer, A. H. and S. F. Richard (1981). A Rational Theory of the Size of Government. Journal of Political Economy 89(5), 914-927.

Merino-Castello, A. (2003). Eliciting Consumers' Preferences Using Stated Preference Discrete-Choice Models: Contingent Ranking versus Choice Experiment. University Pompeu Fabra Economics and Business Working Paper No. 705. 
Milanovic, B. (2000). The Median-Voter Hypothesis, Income Inequality, and Income Redistribution: An Empirical Test with the Required Data. European Journal of Political Economy 16(3), 367-410.

Milesi-Ferretti, G. M., R. Perotti, and M. Rostagno (2002). Electoral Systems and Public Spending. Quarterly Journal of Economics 117, 609-657.

Neustadt, I. and P. Zweifel (2009). Economic Well-Being, Social Mobility, and Preferences for Income Redistribution: Evidence from a Discrete Choice Experiment. SOI Working Paper 0909, University of Zurich, Socioeconomic Institute.

Neustadt, I. and P. Zweifel (2010a). Income Redistribution: How Should the Pie be Divided? SOI Working Paper, forthcoming, University of Zurich, Socioeconomic Institute.

Neustadt, I. and P. Zweifel (2010b). Is the Welfare State Sustainable? Experimental Evidence. SOI Working Paper No. 1003 University of Zurich, Socioeconomic Institute.

Perotti, R. (1996). Growth, Income Distribution and Democracy: What the Data Say. Journal of Economic Growth 1(2), 149-188.

Persson, T. and G. Tabellini (1994). Is Inequality Harmful for Growth? The American Economic Review 84(2), 600-621.

Persson, T. and G. Tabellini (2000). Political Economics: Explaining Economic Policy. MIT Press.

Persson, T. and G. Tabellini (2003). The Economic Effects of Constitutions. Munich Lectures in Economics. MIT Press.

Rainer, H. and T. Siedler (2008). Subjective Income and Employment Expectations and Preferences for Redistribution. Economics Letters 99, 449-453.

Rawls, J. (1999). A Theory of Justice. Belknap Press of Harvard University Press. 
Roberts, K. W. S. (1977). Voting over Income Tax Schedules. Journal of Public Economics 8, 329-340.

Rodriguez, F. C. (1999). Does Distributional Skewness Lead to Redistribution? Evidence from the United States. Economics and Politics 11(2), 171-199.

Romer, T. (1975). Individual Welfare, Majory Voting, and the Properties of a Linear Income Tax. Journal of Public Economics 4, 163-185.

Ryan, M. (2004). A Comparison on Stated Preference Methods for Estimating Monetary Values. Health Economics 13(3), 291-296.

Samuelson, P. A. (1938). A Note on the Pure Theory of Consumer's Behaviour. Economics 5(17), 61-71.

Scheve, K. and D. Stasavage (2006a). Religion and Preferences for Social Insurance. Quarterly Journal of Political Science 1(3), 255-286.

Scheve, K. and D. Stasavage (2006b). The Political Economy of Religion and Social Insurance in the United States, 1910-1939. Studies in American Political Development 20 (Fall), 132-159.

Schläpfer, F., M. Schmitt, and A. Roschewitz (2007). Competitive Politics, Simplified Heuristics, and Preferences for Public Goods. SOI Working Paper No. 0712 University of Zurich, Socioeconomic Institute.

Stutzer, A., L. Goette, and M. Zehnder (2007). Active Decisions and Pro-Social Behavior. Working Paper No. 07-13, Federal Reserve Bank of Boston.

Telser, H. (2002). Nutzenmessung im Gesundheitswesen. Kovač, Hamburg.

Weber, M. (1920). Die protestantische Ethik und der Geist des Kapitalismus. Tübingen. 


\section{A Appendix}

Exhibit 1: Status Quo Card (current state of redistribution)

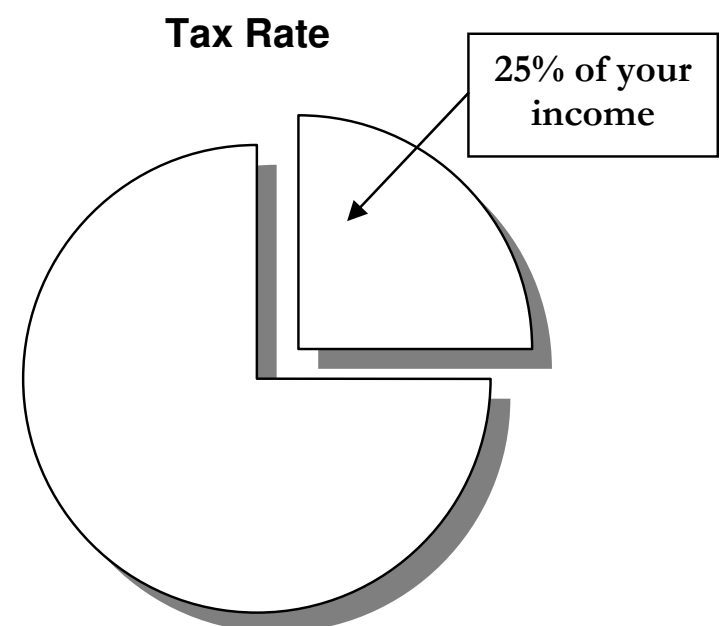

Use of Redistribution
Amount of Redistribution

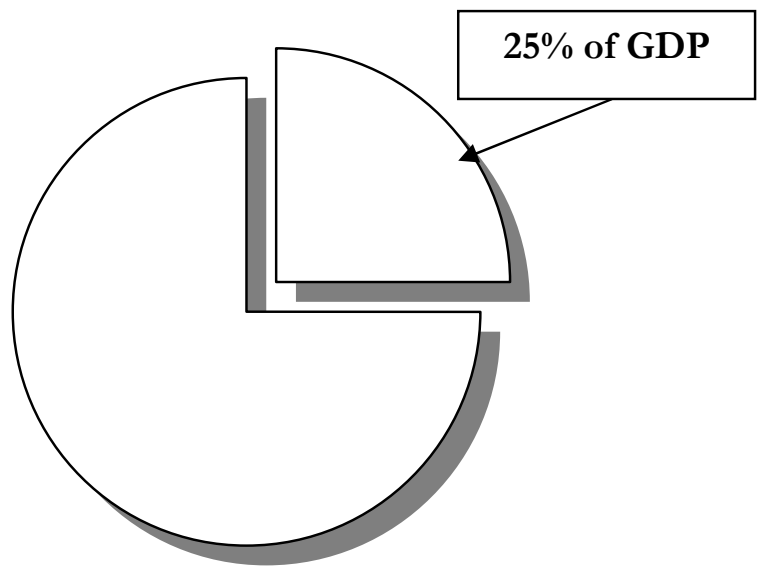

Nationality of Beneficiaries

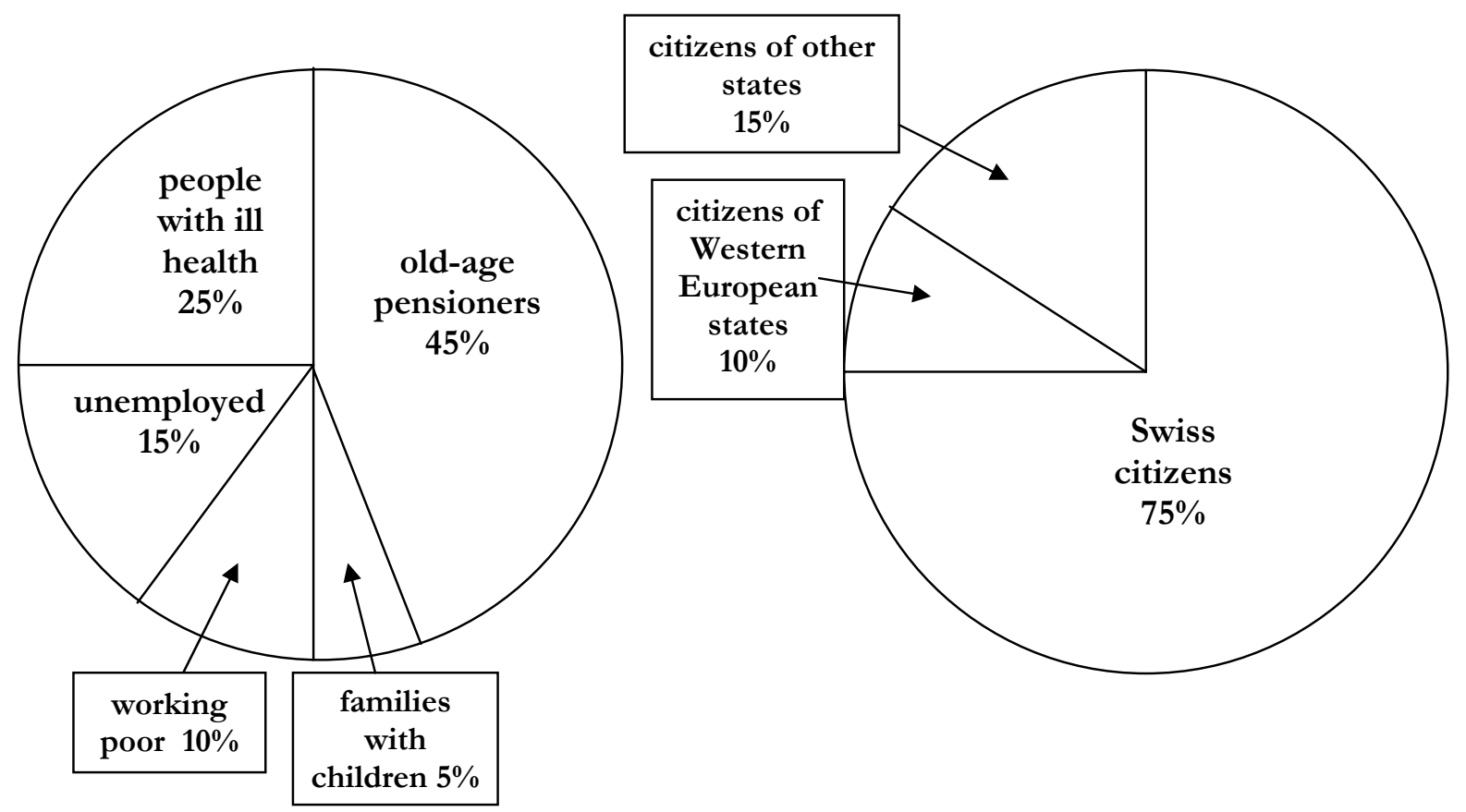


Exhibit 2: Card for Alternative No. 1

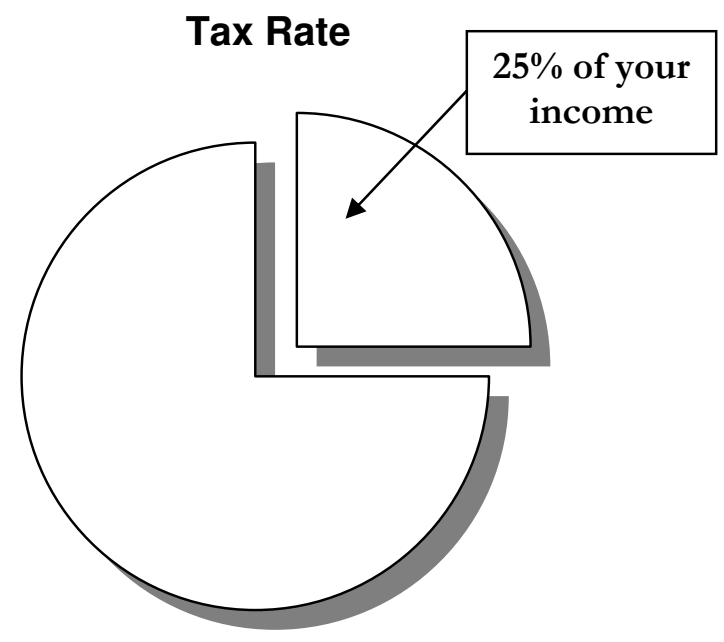

Amount of Redistribution

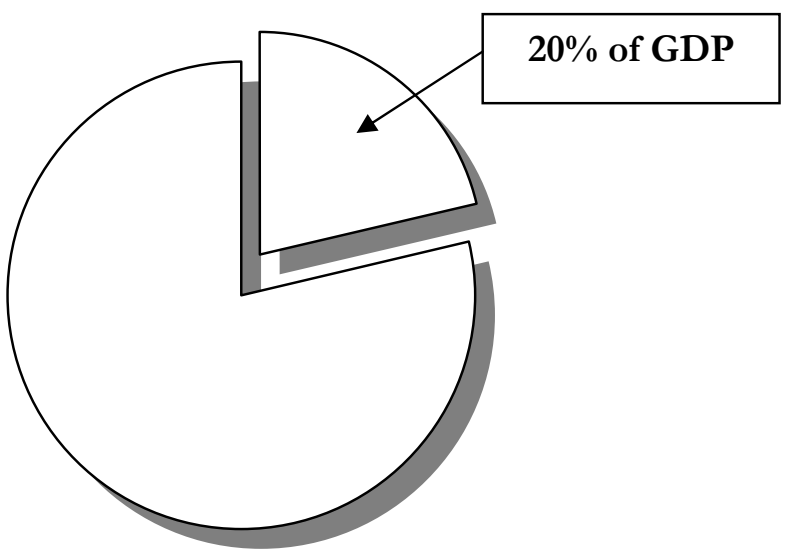

Uses of Redistribution

Nationality of Beneficiaries

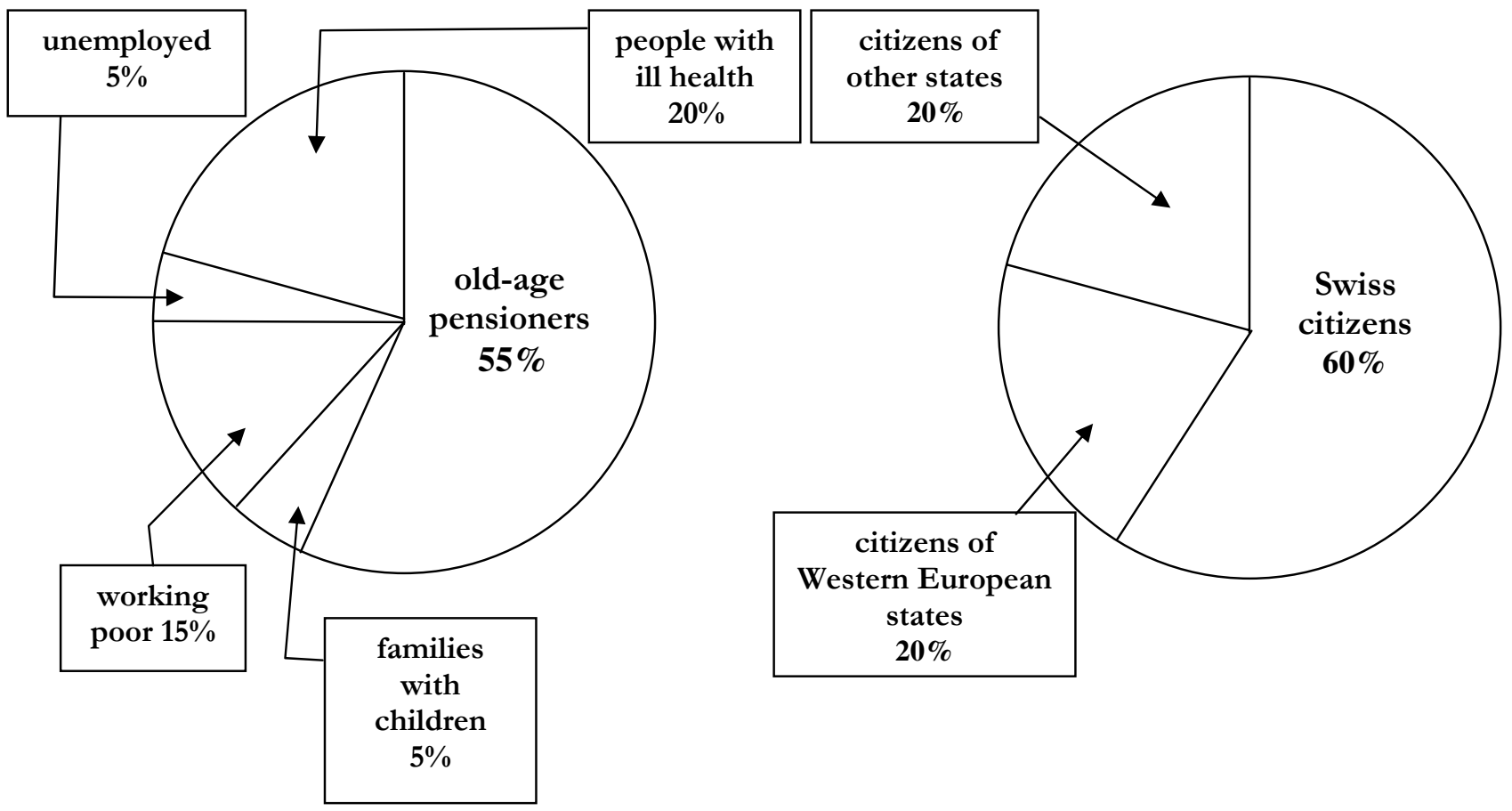


Exhibit 3: Card for Alternative No. 2
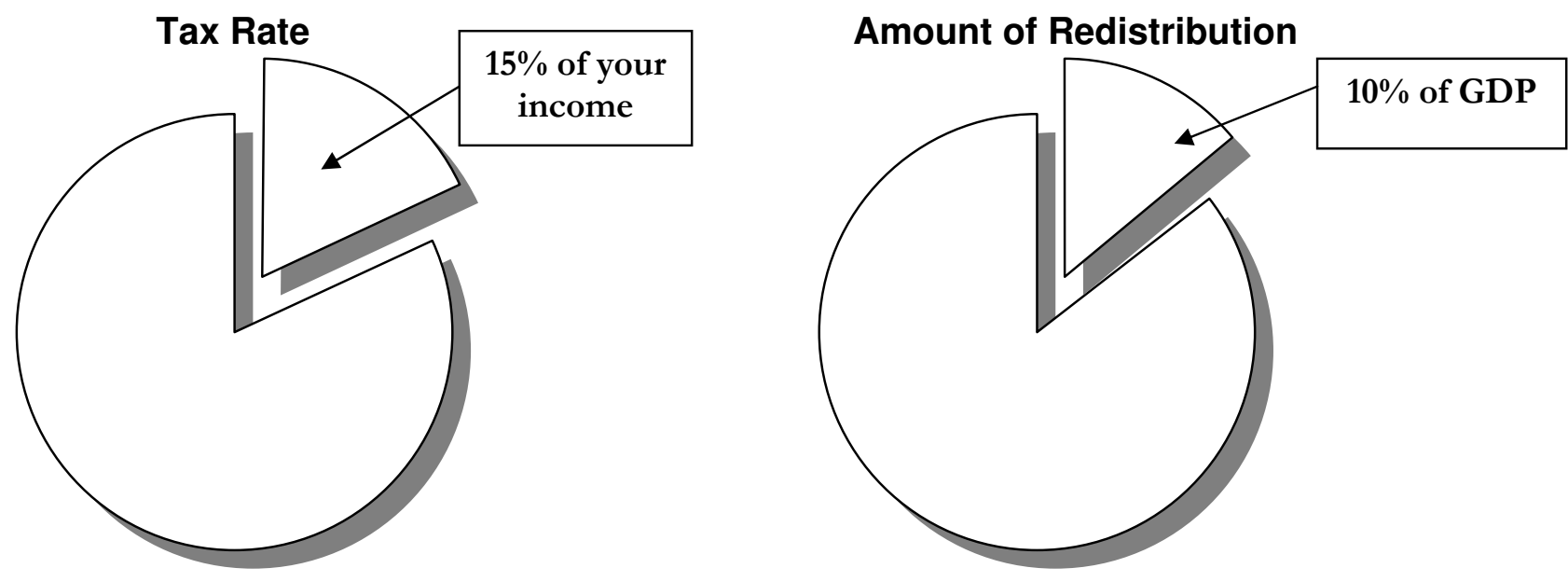

Uses of Redistribution

\section{Nationality of Beneficiaries}
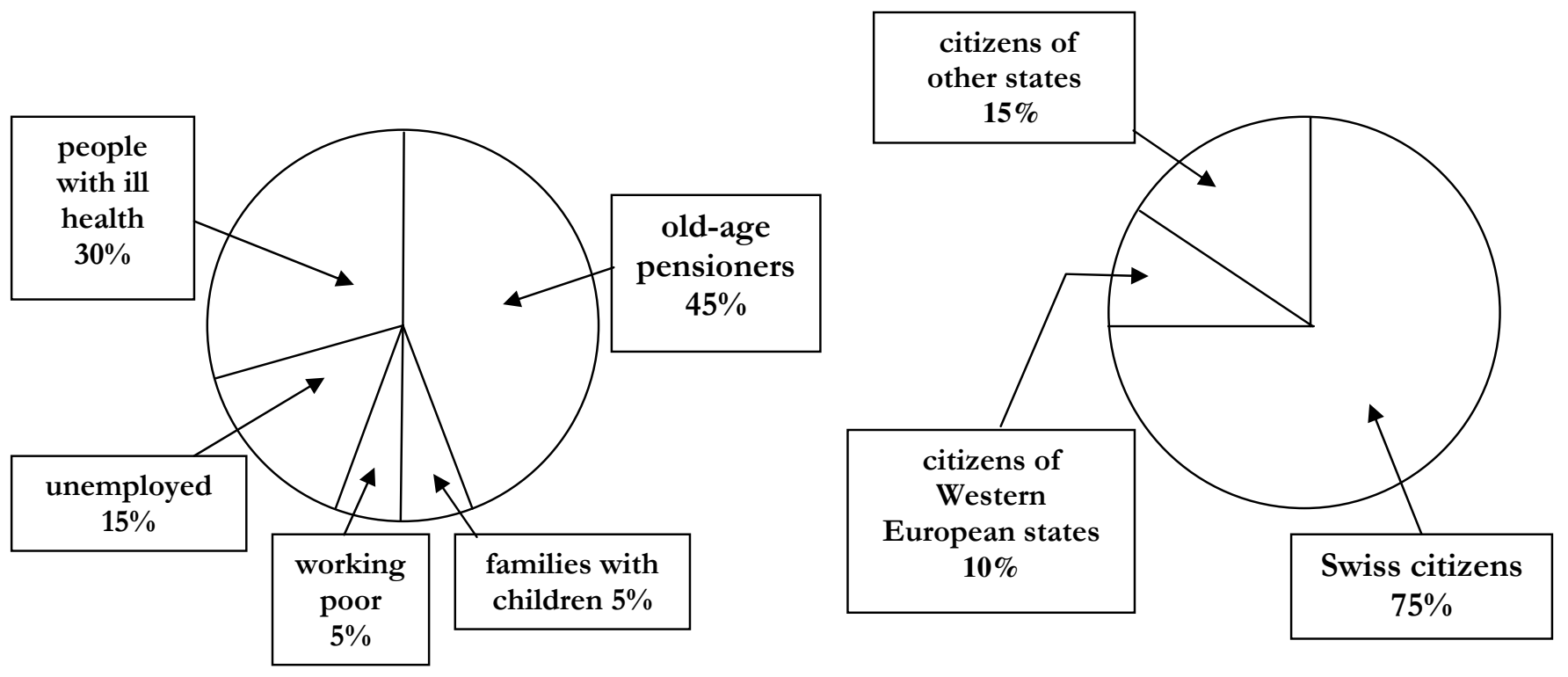
Working Papers of the Socioeconomic Institute at the University of Zurich

The Working Papers of the Socioeconomic Institute can be downloaded from http://www.soi.uzh.ch/research/wp_en.html

1009 Do Religious Beliefs Explain Preferences for Income Redistribution? Experimental Evidence, Ilja Neustadt, September 2010, 36 p.

1008 Lobbying and the Power of Multinational Firms, Andreas Polk, Armin Schmutzler, Adrian Muller, August 2010, 32 p.

1007 When Are Preferences Consistent? The Effects of Task Familiarity and Contextual Cues on Revealed and Stated Preferences, Felix Schläpfer, Baruch Fischhoff, August 2010, $20 \mathrm{p}$.

1006 Golden Balls: A Prisoner's Dilemma Experiment, Donja Darai, Silvia Grätz, July 2010, $47 \mathrm{p}$.

1005 Probability Weighting as Evolutionary Second-best, Florian Herold, Nick Netzer, July 2010, $32 \mathrm{p}$.

1004 Trade Openness, Gains from Variety and Government Spending, Sandra Hanslin, April 2010, $46 \mathrm{p}$.

1003 Is the Welfare State Sustainable? Experimental Evidence on Citizens' Preferences for Income Redistribution, Ilja Neustadt, Peter Zweifel, March 2010, 32 p.

1002 Preferences for Health Insurance in Germany and the Netherlands - A Tale of Two Countries, Peter Zweifel, Karolin Leukert, Stephanie Berner, March 2010, 22 p.

1001 Convex Treatment Response and Treatment Selection, Stefan Boes, January 2010, $28 \mathrm{p}$.

0920 Bounds on Counterfactual Distributions Under Semi-Monotonicity Constraints, Stefan Boes, December 2009, 38 p.

0919 Rotten Kids with Bad Intentions, Nick Netzer, Armin Schmutzler, December 2009, $38 \mathrm{p}$.

0918 Partial Identification of Discrete Counterfactual Distributions with Sequential Update of Information, Stefan Boes, December 2009, 37 p.

0917 How much do journal titles tell us about the academic interest and relevance of economic reserach? An empirical analysis. Felix Schläpfer, December 2009, 14 p.

0916 Fine Tuning of Health Insurance Regulation: Unhealthy Consequences for an Individual Insurer, Johannes Schoder, Michèle Sennhauser, Peter Zweifel, August 2009, 18 p.

0915 Capping Risk Adjustment?, Patrick Eugster, Michèle Sennhauser, Peter Zweifel, September 2009, $27 \mathrm{p}$.

0914 A Pharmaceutical Innovation: Is it Worth the Money? Whose Money?, Michèle Sennhauser, Peter Zweifel, September 2009, 22 p.

0913 Copula-based bivariate binary response models, Rainer Winkelmann, August 2009, $26 \mathrm{p}$.

0912 Simulating WTP Values from Random-Coefficient Models, Maurus Rischatsch, July 2009, $6 \mathrm{p}$.

0911 Physician dispensing and the choice between generic and brand-name drugs - Do margins affect choice?, Maurus Rischatsch, Maria Trottmann, July 2009, 15 p.

0910 GPs' preferences: What price fee-for-service?, Peter Zweifel, Maurus Rischatsch, Angelika Brändle, July 2009, 21 p.

0909 Social Mobility and Preferences for Income Redistribution: Evidence from a Discrete Choice Experiment, Ilja Neustadt, Peter Zweifel, July 2009, 31 p.

0908 Robust estimation of zero-inflated count models, Kevin E. Staub, Rainer Winkelmann June 2009, 22 p. 
0907 Competitive Screening in Insurance Markets with Endogenous Wealth Heterogeneity, Nick Netzer, Florian Scheuer, April 2009, 28 p.

$0906 \quad$ New Flight Regimes and Exposure to Aircraft Noise: Identifying Housing Price Effects Using a Ratio-of-Ratios Approach, Stefan Boes, Stephan Nüesch, April 2009, 40 p.

0905 Patents versus Subsidies - A Laboratory Experiment, Donja Darai, Jens Großer, Nadja Trhal, March 2009, 59 p.

0904 Simple tests for exogeneity of a binary explanatory variable in count data regression models, Kevin E. Staub, February 2009, 30 p.

0903 Spurious correlation in estimation of the health production function: A note, Sule Akkoyunlu, Frank R. Lichtenberg, Boriss Siliverstovs, Peter Zweifel, February 2009, $13 \mathrm{p.}$

0902 Making Sense of Non-Binding Retail-Price Recommendations, Stefan Bühler, Dennis L. Gärtner, February 2009, 30 p.

0901 Flat-of-the-Curve Medicine - A New Perspective on the Production of Health, Johnnes Schoder, Peter Zweifel, January 2009, 35 p.

0816 Relative status and satisfaction, Stefan Boes, Kevin E. Staub, Rainer Winkelmann, December 2008, 11 p.

0815 Delay and Deservingness after Winning the Lottery, Andrew J. Oswald, Rainer Winkelmann, December 2008, 29 p.

0814 Competitive Markets without Commitment, Nick Netzer, Florian Scheuer, November 2008, 65 p.

0813 Scope of Electricity Efficiency Improvement in Switzerland until 2035, Boris Krey, October 2008, 25 p.

0812 Efficient Electricity Portfolios for the United States and Switzerland: An Investor View, Boris Krey, Peter Zweifel, October 2008, 26 p.

0811 A welfare analysis of "junk" information and spam filters; Josef Falkinger, October 2008, 33 p.

0810 Why does the amount of income redistribution differ between United States and Europe? The Janus face of Switzerland; Sule Akkoyunlu, Ilja Neustadt, Peter Zweifel, September 2008, 32 p.

0809 Promoting Renewable Electricity Generation in Imperfect Markets: Price vs. Quantity Policies; Reinhard Madlener, Weiyu Gao, Ilja Neustadt, Peter Zweifel, July 2008, $34 \mathrm{p}$.

0808 Is there a U-shaped Relation between Competition and Investment? Dario Sacco, July 2008, 26p.

$0807 \quad$ Competition and Innovation: An Experimental Investigation, May 2008, 20 p.

0806 All-Pay Auctions with Negative Prize Externalities: Theory and Experimental Evidence, May 2008, 31 p.

$0805 \quad$ Between Agora and Shopping Mall, Josef Falkinger, May 2008, 31 p.

0804 Provision of Public Goods in a Federalist Country: Tiebout Competition, Fiscal Equalization, and Incentives for Efficiency in Switzerland, Philippe Widmer, Peter Zweifel, April 2008, 22 p.

0803 Stochastic Expected Utility and Prospect Theory in a Horse Race: A Finite Mixture Approach, Adrian Bruhin, March 2008, 25 p.

0802 The effect of trade openness on optimal government size under endogenous firm entry, Sandra Hanslin, March 2008, 31 p.

0801 Managed Care Konzepte und Lösungsansätze - Ein internationaler Vergleich aus schweizerischer Sicht, Johannes Schoder, Peter Zweifel, February 2008, 23 p.

0719 Why Bayes Rules: A Note on Bayesian vs. Classical Inference in Regime Switching Models, Dennis Gärtner, December 2007, 8 p. 